\title{
Generation and Characterization of Mice Deficient in Hepsin, a Hepatic Transmembrane Serine Protease
}

\author{
Qingyu Wu, ${ }^{\star}$ Dongyin Yu, ${ }^{\star}$ Joseph Post, ${ }^{\ddagger}$ Meredith Halks-Miller, ${ }^{\ddagger}$ J. Evan Sadler, ${ }^{\S}$ and John Morser* \\ *Department of Cardiovascular Research and ${ }^{\ddagger}$ Department of Pharmacology, Berlex Biosciences, Richmond, California $94804 ;$ and \\ ${ }^{\S}$ Department of Medicine and ${ }^{\|}$Department of Biochemistry and Molecular Biophysics, Howard Hughes Medical Institute, Barnes-Jewish \\ Hospital, Washington University School of Medicine, St. Louis, Missouri 63110
}

\begin{abstract}
Hepsin is a type II transmembrane serine protease highly expressed on the surface of hepatocytes. The physiological function of hepsin is not known, although in vitro studies indicate that hepsin plays a role in the initiation of blood coagulation and in hepatocyte growth. To determine the functional importance of hepsin, we generated hepsin-deficient mice by homologous recombination. Homozygous hepsin ${ }^{-1-}$ mice were viable and fertile, and grew normally. In functional assays including tail bleeding time, plasma clotting times, and tissue factor- or LPS-induced disseminated intravascular coagulation models, no significant difference was found between hepsin ${ }^{-1-}$ and wild-type litter mates. Liver weight and serum concentrations of liver-derived proteins or enzymes were similar in hepsin ${ }^{-1-}$ and wild-type mice. Interestingly, serum concentrations of bone-derived alkaline phosphatase were approximately twofold higher in hepsin $^{-1-}$ mice of both sexes when compared with wild-type litter mates. No obvious abnormalities were found in major organs in hepsin ${ }^{-1-}$ mice in histological examinations. Our results indicate that hepsin is not essential for embryonic development and normal hemostasis. Hepsin ${ }^{-1-}$ mice will help to evaluate the long-term effects of hepsin deficiency in these animals. (J. Clin. Invest. 1998. 101:321-326.) Key words: gene targeting • embryonic stem cells • homologous recombination $\bullet$ factor $\mathrm{VII} \bullet$ hepatocyte
\end{abstract}

\section{Introduction}

Membrane proteases participate in a variety of important biological events, including development, tissue remodeling, wound healing, cytokine processing, and tumor invasion (1-3). Hepsin is a novel serine protease with a transmembrane domain near the amino terminus $(4,5)$. This structural feature distinguishes hepsin from most serine proteases of the trypsin superfamily $(6,7)$. In Drosophila melanogaster, Stubble-stubbloid protein, a transmembrane serine protease, has a struc-

A preliminary report describing a portion of this work has appeared in abstract form (1997. Thromb. Haemostasis. [Suppl.]:756a).

Address correspondence to Qingyu Wu, M.D., Ph.D., Berlex Biosciences, 15049 San Pablo Avenue, Richmond, CA 94804. Phone: 510-669-4737; FAX: 510-669-4246; E-mail: Qingyu_Wu@Berlex.com

Received for publication 27 August 1997 and accepted in revised form 11 November 1997.

J. Clin. Invest.

(C) The American Society for Clinical Investigation, Inc. 0021-9738/98/01/0321/06 \$2.00

Volume 101, Number 2, January 1998, 321-326

http://www.jci.org ture similar to that of hepsin (8). Genetic studies demonstrate that defects in the Stubble-stubbloid gene lead to malformation of legs, wings, and bristles in the fruitfly (9).

Biochemical studies including proteolytic digestion and membrane fractionation show that hepsin is a type II transmembrane serine protease mainly expressed on the surface of hepatocytes (10-12). Low levels of hepsin mRNA have been detected in kidney, pancreas, lung, and prostate, but the cell types that express hepsin mRNA in these tissues are unknown. In addition to normal tissues, hepsin gene expression was found in several tumor cell lines, including hepatoma cell lines HepG2 and PLC/PRF/5, mammary carcinoma cell lines MCF784 and T470, and epithelioid HeLa S3 carcinoma cells $(11,13)$. Recently, hepsin was reported to be frequently overexpressed in ovarian carcinomas (14).

The physiological function of hepsin is unknown, although biochemical studies indicate that hepsin may play a role in the initiation of blood coagulation. Kazama et al. reported that recombinant human hepsin expressed on the surface of BHK cells activated blood coagulation factor VII (FVII) ${ }^{1}$ (15). The reaction was highly specific since hepsin did not activate other structurally related proteases such as factors IX and $\mathrm{X}$, prothrombin, and protein $\mathrm{C}$ under similar experimental conditions. Hepsin-mediated FVII activation was shown to be sufficient to initiate the coagulation pathway leading to thrombin formation (15).

In addition, hepsin may participate in other biological processes such as cell growth or tissue remodeling. Torres-Rosado et al. reported that hepsin is required for the growth of human hepatocytes (13). In a cell culture system, addition of a polyclonal anti-hepsin antibody or hepsin-specific antisense oligonucleotides significantly altered the morphology of HepG3 cells and inhibited their growth (13). These results suggest that hepsin functions either directly as a growth factor or indirectly as an enzyme that processes a growth factor(s) for hepatocytes.

To evaluate the biological importance of hepsin, we have generated hepsin-deficient mice by gene targeting technology. Homozygous hepsin ${ }^{-1-}$ mice were viable and fertile, and did not exhibit obvious defects in growth, liver function, and blood coagulation. Our results show that hepsin is not essential for embryonic development, organogenesis, and hemostasis.

\section{Methods}

The murine hepsin gene and the targeting vector. Murine hepsin cDNAs were isolated by PCR amplification and screening of murine liver

1. Abbreviations used in this paper: aPTT, activated partial thromboplastin time; DIC, disseminated intravascular coagulation; FVII, factor VII; GGT, $\gamma$-glutamyltranspeptidase; PT, prothrombin time; SGPT, serum glutamic pyruvic transaminase. 
cDNA libraries (16). The full-length murine hepsin cDNA was $\sim 1.6$ $\mathrm{kb}$ in length and shared $84 \%$ sequence identity with human hepsin cDNA (4). The hepsin cDNAs were used to screen a 129Sv genomic DNA library (Stratagene Inc., La Jolla, CA) to clone the mouse hepsin gene. To construct a targeting vector, a 4-kb KpnI/BamHI fragment in the hepsin gene was replaced by a neomycin (neo) expression cassette driven by the murine phosphoglycerate kinase promoter (17) (see Fig. $1 A$ ). At the $3^{\prime}$ end of the vector, a herpes simplex virus thymidine kinase $(t k)$ gene cassette was included to serve as a negative selection marker (18) (Fig. $1 A$ ).

Targeting of the hepsin gene in mouse embryonic stem (ES) cells. $30 \mu \mathrm{g}$ of linearized plasmid vector DNA was introduced into ES cells (RW4; Genome Systems, St. Louis, MO) by electroporation using an Electro Cell Manipulator (ECM 600; BTX Inc., San Diego, CA). Transfected ES cells $\left(1.5 \times 10^{7}\right)$ were selected in the presence of $250 \mu \mathrm{g} / \mathrm{ml}$ G418 (Life Technologies, Gaithersburg, MD) and $2 \mu \mathrm{M}$ ganciclovir (Syntex Lab., Inc., Palo Alto, CA). Stable clones from the selection were screened for homologous recombination by Southern blotting using a genomic probe flanking the hepsin gene deletion (see Fig. 1 $A$ ). Additional Southern analysis was performed using a neo probe to exclude the presence of random insertions of the neo gene in the genome of mutant ES cells.

Generation of chimeric mice and germline transmission of the mutant allele. Mutant ES clones were microinjected into blastocysts from C57BL $/ 6 \mathrm{~J}$ mice. Chimeric male offspring with $>50 \%$ coat color chimerism were bred with National Institutes of Health (NIH) Swiss females to establish germline transmission of the mutant hepsin allele. Genotyping was performed by PCR using $100 \mathrm{ng}$ genomic DNA isolated from tail or ear biopsies. Oligonucleotide primers for both neo gene (5'-CAA GAT GGA TTG CAC GCA GG-3' and 5'-GTA AAG CAC GAG GAA GCG G-3') and the hepsin gene (5'-ACG GCA CAT CGG GCT TCT TTT-3' and 5'-AAT GCG GTC CAC CGG CAG CTT CCT-3') were included in the reactions. The PCR results were confirmed by Southern analysis of EcoRI digested DNA samples using the hepsin genomic probe. All mice in this study were maintained in an animal facility accredited by the Association for Assessment and Accreditation of Laboratory Animal Care International (AAALACI).

Northern analysis of hepsin $m R N A$ expression. Total RNA was extracted from frozen liver tissue using the Ultraspec ${ }^{\mathrm{TM}}$ RNA kit (Biotecx Laboratories Inc., Houston, TX). Samples (15 $\mu \mathrm{g})$ were fractionated on denaturing agarose gels, transferred onto nitrocellulose membranes, and hybridized with ${ }^{32} \mathrm{P}$-labeled mouse hepsin cDNA probes spanning the entire coding region. To determine mRNA expression of other liver specific genes, the blot was reprobed with a partial mouse prothrombin cDNA that was PCR-amplified based on the published sequence (19).

Hemostasis assays and blood chemistry analysis. Blood samples were drawn from the inferior vena cava into $1 / 10$ volume of $3.8 \%$ sodium citrate. Blood cell counts and hematocrit were analyzed using a hemostasis instrument (9210 CP Baker System, Allentown, PA). Clotting assays (activated partial thromboplastin time and prothrombin time [aPTT and PT]) were performed with platelet poor plasma using the MLA Electra 900C programmable coagulometer (Pleasantville, NY). In the tail-bleeding assay, mice were anesthetized with pentobarbital $(90 \mathrm{mg} / \mathrm{kg})$. The tip of the mouse tail (1 mm in diameter) was cut. Tails were soaked immediately in $0.9 \% \mathrm{NaCl}$ saline prewarmed at $37^{\circ} \mathrm{C}$ and the time until bleeding stopped completely was recorded. For blood chemistry analysis, serum samples were prepared from clotted whole blood. Chemistry analysis was performed by Consolidated Veterinary Diagnostics, Inc. (West Sacramento, CA). Alkaline phosphatase isoenzymes were analyzed by a quantitative method described by Koffmann et al. (20).

LPS-induced septic shock and thromboplastin-induced disseminated intravascular coagulation (DIC). In the LPS-induced septic shock model, mice (13-14 wk old) were injected intraperitoneally with $40 \mathrm{mg} / \mathrm{kg}$ of LPS from Escherichia coli serotype O111:B4 (Calbiochem Corp., La Jolla, CA). The mice were monitored for signs of endotoxemia and lethality four times a day for the first $3 \mathrm{~d}$ and periodically thereafter. In the thromboplastin-induced DIC model, anesthetised mice were injected intravenously with human placental thromboplastin (Behring, Marburg, Germany). The linear range of the thromboplastin dose was determined experimentally. The time in minutes was recorded between the injection of thromboplastin and acute death as measured by cessation of breathing or heart beating.

Histological analysis. Mice were killed under $\mathrm{CO}_{2}$ narcosis and tissues were fixed by perfusion through the heart with an aldehyde fixative consisting of $4 \%(\mathrm{wt} / \mathrm{vol})$ paraformaldehyde, $3 \%(\mathrm{wt} / \mathrm{vol})$ sucrose, in $0.1 \mathrm{M}$ phosphate buffer, $\mathrm{pH}$ 7.3. Tissues were dehydrated in graded ethanol solutions and embedded in paraffin blocks. Tissue sections were cut at $5-\mu \mathrm{m}$ thickness, stained with hematoxylin and eosin (H \& E), and examined by light microscopy.

\section{Results}

Disruption of the hepsin gene in ES cells and generation of chimeric mice. An 18-kb DNA fragment that contained the mouse hepsin gene was isolated from a 129Sv genomic library. The hepsin gene contains at least 12 exons (Fig. $1 A$ ). The serine protease active site residues, His, Asp, and Ser are encoded by exons 7, 8, and 11, respectively. A replacement targeting vector was constructed by deleting the $\mathrm{KpnI} / \mathrm{BamHI}$ fragment containing exons 5-8 that code for the conserved activation site and most of the catalytic domain (Fig. $1 A$ ). Over 700 stable ES cell clones transfected with the targeting vector were analyzed by Southern blotting. Seven ES clones were identified in which one copy of the endogenous hepsin gene was disrupted by homologous recombination. Four mutant ES clones were microinjected into blastocysts from C57BL/6J mice to generate chimeric mice. Germline transmission was achieved with nine chimeric mice derived from three independent cell lines. The results of phenotypical analysis were obtained from mice derived from all these three ES cell lines.

Viability, growth, and fertility of homozygous hepsin-1mice. Breeding of hepsin ${ }^{+-}$mice produced over 500 offspring. Genotypes of F2 progeny were determined by PCR analysis and the results were confirmed by Southern blotting in randomly selected samples (Fig. $1 B$ ). Wild-type, hepsin ${ }^{+/-}$and hepsin $^{-1-}$ mice represented $24.3,50.0$, and $25.7 \%$ of progeny, respectively. The observed Mendelian pattern of inheritance indicates that homozygous hepsin deficiency is compatible with normal embryonic development. Male to female ratio was $\sim 1: 1$ in wild-type, hepsin ${ }^{+/-}$, and hepsin ${ }^{-1-}$ mice. The absence of hepsin mRNA expression in liver samples from hepsin ${ }^{-1-}$ mice was demonstrated by Northern analysis using cDNA probes spanning the entire coding region (Fig. $1 C$ ). As a control, the expression of prothrombin mRNA in the liver from hepsin ${ }^{-1-}$ mice was not significantly affected (Fig. 1C).

When followed to $10 \mathrm{mo}$, hepsin ${ }^{-1-}$ mice appeared to develop normally and exhibited similar body weight gain as wild-type and hepsin ${ }^{+/-}$litter mates. No obvious physical abnormalities were observed in hepsin ${ }^{-1-}$ mice. In hematologic examinations, values for red blood cell, white blood cell, and platelet counts, hematocrit and hemoglobin were similar in hepsin ${ }^{-1-}$ mice and wild-type controls (data not shown). Both male and female hepsin ${ }^{-1-}$ mice were fertile and produced viable offspring.

Tail bleeding and plasma clotting assays in hepsin ${ }^{-1-}$ mice. To evaluate the physiological importance of hepsin function in blood coagulation, tail bleeding time and plasma clotting times (aPTT and PT) were determined in hepsin ${ }^{-1-}$ mice. The mouse 
$\mathbf{A}$
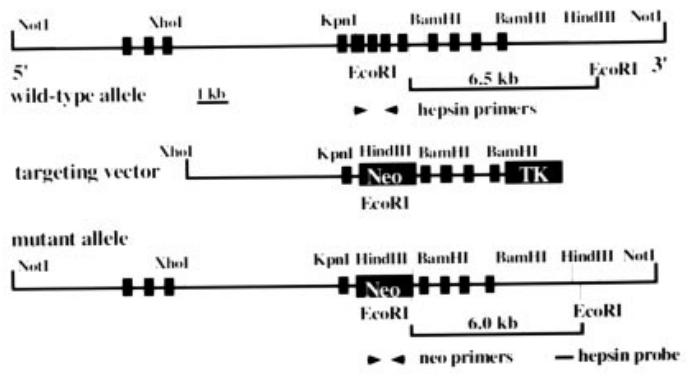

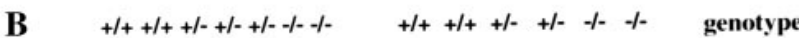
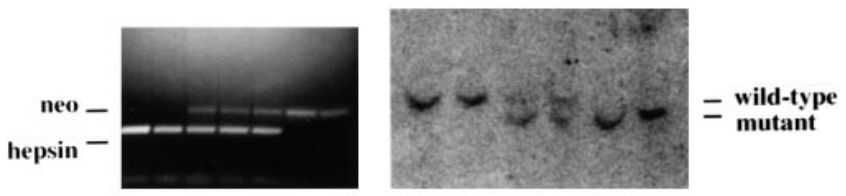

$\mathbf{C}$

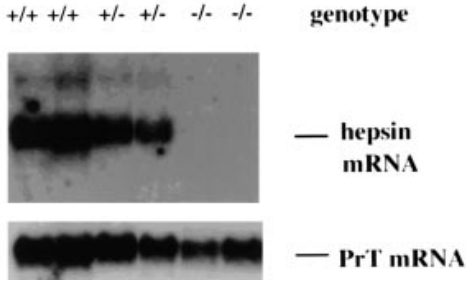

Figure 1. Disruption of the mouse hepsin gene by homologous recombination. (A) Structure of the hepsin gene and the targeting vector. Exons (black boxes) and selected restriction sites in the hespin gene (wild-type allele) are indicated (top panel). The targeting vector was constructed by replacing of the KpnI/BamHI fragment with a neo gene cassette. A $t k$ gene cassette was included at the $3^{\prime}$ end of the vector. The predicted genomic structure after homologous recombination (mutant allele) is shown. Locations of oligonucleotide primers for PCR analysis and a hepsin genomic probe for Southern blotting are indicated. (B) Genotyping by PCR and Southern analyses. Genomic DNA was isolated from tail or ear biopsies. Genotypes were determined by PCR (left) and Southern (right) analyses. In the PCR reactions, oligonucleotide primers specific for the neo and wild-type hepsin genes were included. The PCR products were visualized in an agarose gel stained with ethdium bromide. DNA fragments from neo or hepsin genes represent the mutant or wild-type alleles, respectively. For Southern blotting, genomic DNA was digested with EcoRI and hybridized with the hepsin genomic probe $(A)$. DNA fragments of the expected size from wild-type and mutant hepsin alleles are indicated. $(C)$ Northern analysis of hepsin mRNA expression. Total RNA was isolated from liver samples from wild-type, heterozygous, and homozygous mice. Northern blot was probed with a mouse hepsin cDNA. Hepsin mRNA was detected in wild-type and heterozygous mice but not in homozygous mice (top panel). As a control, the same blot was reprobed with a mouse prothrombin $(\operatorname{Pr} T)$ cDNA. The expression of mouse prothrombin mRNA was not affected in hepsin $^{-/-}$mice (lower panel).

tail bleeding time measures both platelet and blood-clotting activities, whereas aPTT and PT assays measure the function of the intrinsic and extrinsic blood coagulation pathways, respectively. As shown in Table I, no prolongation in time was detected in hepsin ${ }^{-1-}$ mice in these three assays, indicating that
Table I. Functional Hemostasis Assays in Wild-type and Hepsin-deficient Mice

\begin{tabular}{lcc}
\hline & Hepsin $^{+/+}$ & Hepsin $^{-/-}$ \\
\hline Tail bleeding time (s) & $70.6 \pm 19.7$ & $77.3 \pm 28.7$ \\
& $(n=5)$ & $(n=7)$ \\
PT (s) & $20.9 \pm 6.6$ & $22.6 \pm 4.5$ \\
& $(n=6)$ & $(n=5)$ \\
aPTT (s) & $37.2 \pm 11.2$ & $38.4 \pm 9.1$ \\
& $(n=9)$ & $(n=6)$ \\
Thromboplastin-induced DIC: & & \\
cessation of breathing (min) & $1.30 \pm 0.16$ & $1.42 \pm 0.42$ \\
& $(n=5)$ & $(n=6)$ \\
cessation of heart beating (min) & $1.86 \pm 0.34$ & $1.97 \pm 0.45$ \\
& $(n=5)$ & $(n=6)$
\end{tabular}

The tail bleeding time, plasma prothrombin time $(P T)$ and activated partial thromboplastin time ( $a P T T)$ were performed with 9-12-wk-old mice, as described in Methods. In the thromboplastin-induced DIC model, acute death was ascertained as cessation of either breathing or heart beating. Data are presented as mean $\pm \mathrm{SD}$ and the number of mice in each experimental group is indicated in parentheses.

hepsin deficiency did not adversely affect hemostasis. These results are consistent with the observation that no spontaneous bleedings occurred in hepsin ${ }^{-1-}$ mice.

Thromboplastin-induced DIC and LPS-induced septic shock models. To examine the potential function of hepsin under pathological conditions, hepsin ${ }^{-1-}$ mice were challenged in DIC and septic shock models. In the DIC model, thromboplastin was injected intravenously. The times at which breathing or heart beating stopped were similar in both hepsin ${ }^{-1-}$ mice and wild-type controls (Table I), indicating that the tissue factordependent coagulation pathway was not altered in hepsin ${ }^{-/-}$ mice. This was supported by the results from a septic shock model, in which survival rates of hepsin ${ }^{-1-}$ and wild-type mice after injection of a high dose of LPS were not significantly different (Fig. 2).

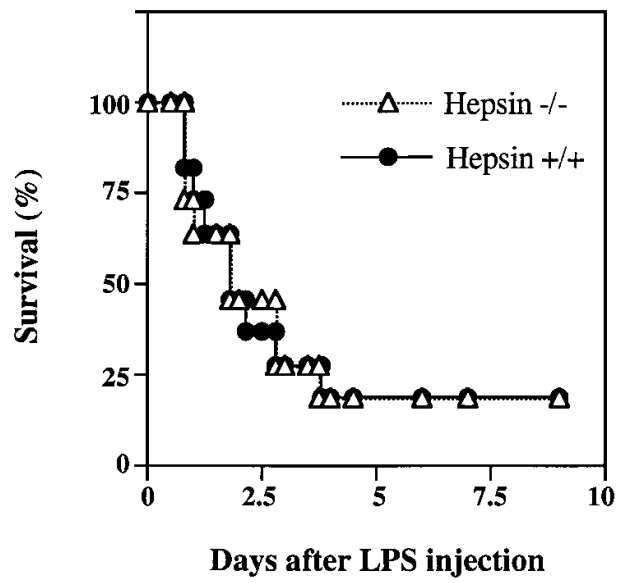

Figure 2. Survival of hepsin-deficient and wild-type mice after LPS injection. Mice were injected intraperitoneally with LPS $(40 \mathrm{mg} / \mathrm{kg})$ to test their response to septic shock. The percentage of surviving mice was recorded over time. The data shown are from two independent experiments with a total of $11 \mathrm{hepsin}^{+/+}$(filled dots and solid line) and 11 hepsin $^{-1}$ (open triangles and dotted line) mice. 
Table II. Liver Weight and Blood Chemistry Analysis for Liver Function

\begin{tabular}{lcc}
\hline & Hepsin $^{+/+}$ & Hepsin \\
\hline Liver weight (grams) & $0.96 \pm 0.13$ & $0.92 \pm 0.08$ \\
& $(n=6)$ & $(n=5)$ \\
SGPT (IU/liter) & $25.75 \pm 8.27$ & $31.38 \pm 7.86$ \\
& $(n=28)$ & $(n=29)$ \\
GGT (IU/liter) & $0.71 \pm 0.75$ & $1.0 \pm 0.58$ \\
& $(n=7)$ & $(n=7)$ \\
Total protein (grams/dl) & $5.48 \pm 0.28$ & $4.87 \pm 0.43$ \\
& $(n=8)$ & $(n=13)$ \\
Albumin (grams/dl) & $2.81 \pm 0.24$ & $2.32 \pm 0.15$ \\
& $(n=18)$ & $(n=13)$ \\
Globulin (grams/dl) & $2.67 \pm 0.22$ & $2.55 \pm 0.31$ \\
& $(n=18)$ & $(n=13)$ \\
Total bilirubin (mg/dl) & $0.17 \pm 0.07$ & $0.13 \pm 0.07$ \\
& $(n=14)$ & $(n=11)$
\end{tabular}

Wild-type and hepsin ${ }^{-1-}$ mice (8-12-wk old) were killed under $\mathrm{CO}_{2}$ narcosis. The liver was dissected out and weighed. Blood chemistry analysis was performed as described in Methods. Data are presented as mean \pm SD and the number of mice in each experimental group is indicated in parentheses.

Blood chemistry analysis for liver function. In addition to blood coagulation, hepsin was reported to be required for growth of hepatocytes in vitro (13). To examine the effects of hepsin deficiency on liver function, blood samples from hepsin-deficient mice were analyzed. As shown in Table II, serum concentrations of alanine aminotransferase (SGPT), $\gamma$-glutamyltranspeptidase (GGT), bilirubin, albumin, globulin, and total protein were similar in hepsin ${ }^{-1-}$ and wild-type mice, and values were within the normal ranges. Interestingly, serum alkaline phosphatase levels were approximately twofold higher in hepsin ${ }^{-1-}$ mice when compared with wild-type litter mates (Fig. 3). The elevation of serum alkaline phosphatase was found in both male and female hepsin ${ }^{-1-}$ mice at different ages (Fig. 3). Alkaline phosphatase isoenzymes were analyzed, and results indicated that the elevated alkaline phosphatase in the serum from hepsin ${ }^{-1-}$ mice was mostly of bone origin (Fig. 4).

Morphologic and histologic analyses. Necropsies and histologic examinations were performed on hepsin ${ }^{-1-}$ mice at various ages. No gross abnormalities were indentified in major organs including liver, brain, lung, heart, kidney, pancreas, spleen, and bone. Livers from hepsin ${ }^{-1-}$ and wild-type mice appeared similar and had comparable weights (Table II). In $\mathrm{H}$ \& E-stained sections, tissues including liver and bone from hepsin ${ }^{-1-}$ mice were histologically indistinguishable from those of wild-type mice (data not shown). X-ray examinations were also performed to detect potential defects in the skeleton. No structural abnormalities were found in long bones, pelvis, and vertebrae in hepsin ${ }^{-1-}$ mice at the age of 5 mo (data not shown).

\section{Discussion}

Human recombinant hepsin expressed on the surface of BHK cells has been reported to specifically activate FVII (15), an essential enzyme that acts at the top of the tissue factor-depen-
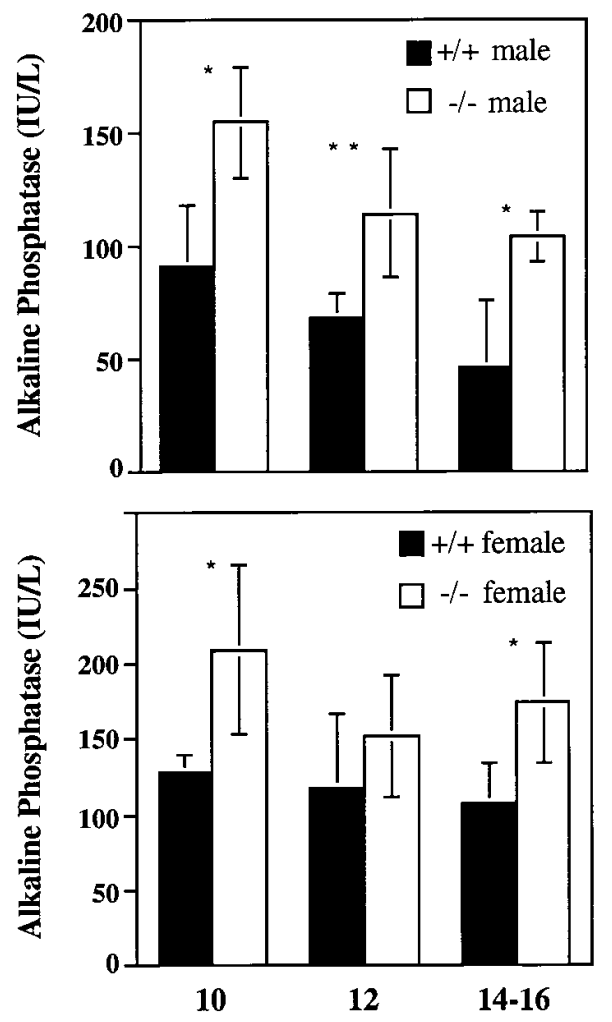

Age (week)

Figure 3. Serum alkaline phosphatase levels in hepsin-deficient and control mice. Serum samples were prepared from male (top) and female (bottom) hepsin ${ }^{-1-}$ mice and wild-type litter mates at 10,12, and 14-16 wk of age. The number of mice in each group is four to five. Total serum alkaline phosphatase activity was measured by hydrolysis of $p$-nitrophenylphosphate at $\mathrm{pH} 9.2$ (39). Data are presented as mean \pm SD. Statistical differences between hepsin ${ }^{-1-}$ mice (open bars) and wild-type litter mates (filled bars) are indicated by asterisks: $* P<$ $0.05 ; * * P<0.01$ by Student's $t$ test.

dent coagulation pathway (21). This finding was confirmed in our own studies (data not shown), indicating a potential function of hepsin in the initiation of blood coagulation. Genetic and site-directed mutagenesis studies show that the activation cleavage of the Age152-Ile peptide bond in FVII is required to convert the zymogen to an active enzyme $(22,23)$. The mechanism of FVII activation under physiological conditions is not completely understood. In addition to hepsin, factors IXa, Xa and XIIa, and thrombin have been reported to activate FVII in vitro (24-28). Recent studies with haemophilia patients suggest that FIXa is primarily responsible for the basal levels of FVIIa in vivo (29-31). However, the functional significance of the FVII activation mediated by other enzymes remains unclear at this time.

To evaluate the physiological importance of hepsin, we generated hepsin-deficient mice by gene targeting technology. Hepsin $^{-1-}$ mice were viable and did not bleed spontaneously. Furthermore, no functional defects were detected in the tail bleeding and blood clotting assays. These results suggest that hepsin deficiency did not significantly alter blood coagulation pathways. Due to lack of a suitable assay, we were unable to measure directly plasma FVIIa level in hepsin ${ }^{-1-}$ mice $(32,33)$. 


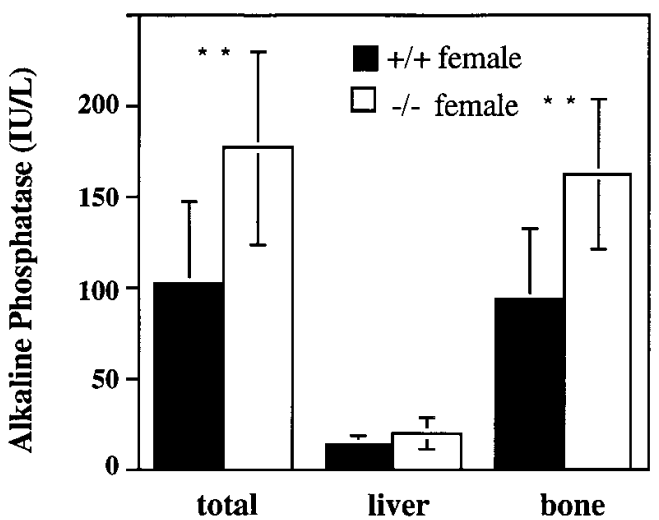

Figure 4. Analysis of alkaline phosphatase isoenzymes. Serum samples were collected from 14-16-wk-old female mice. Total serum alkaline phosphatase activity was assayed by hydrolysis of p-nitrophenylphosphate at pH 9.2 (39). Determination of activity from isoenzymes was based on a quantitative assay described by Hoffmann et al. (20). Data are presented as mean \pm SD from 8 wild-type (filled bars) and 14 hepsin ${ }^{-1-}$ (open bars) mice. Statistical differences are indicated by asterisks, $* * P<0.01$ by Student's $t$ test.

Since the prothrombin time and thromboplastin-induced DIC assays, which depend on FVIIa, were normal in these animals, it is very unlikely that the hepsin-mediated FVII activation is physiologically important.

In addition to FVII activation, hepsin was shown to play a role in hepatocyte growth (13). The observation is intriguing since serine proteases are known to have growth factor-like activities. For example, thrombin is a potent mitogen for vascular fibroblasts and smooth muscle cells (34). Furthermore, several growth factors, such as hepatocyte growth factor (HGF) and the product of growth arrest-specific gene 6 (Gas6), share striking sequence and structural similarities with blood coagulation proteases $(35,36)$, and HGF is critical for the development of several epithelial organs including liver and placenta $(37,38)$. The hepsin-dependent growth of hepatocytes in culture suggests that hepsin may play a role in processes such as cell differentiation and organogenesis. Surprisingly, hepsin ${ }^{-1-}$ mice developed normally. Liver weight and serum levels of liver proteins in hepsin ${ }^{-/-}$mice were similar to those in wild-type controls (Table II). Histological examinations did not identify any structural abnormalities in major organs. These results indicate that the hepatocyte growthstimulating activity of hepsin is not essential for embryonic development and maintenance of normal liver function.

An interesting observation in hepsin ${ }^{-1-}$ mice is that serum alkaline phosphatase is increased in both male and female hepsin $^{-1-}$ mice of various ages (Fig. 3). The significance of this finding is not clear at this time. We consider several possibilities here. First, in humans, elevation of serum alkaline phosphatase is most commonly associated with hepatobiliary disorders. In hepsin ${ }^{-1-}$ mice, however, hepatolibilary disease is unlikely since the livers were histologically normal, and tests of liver function, such as bilirubin, SGPT, GGT (Table II), and liver-derived alkaline phosphatase (Fig. 4), were within normal ranges. Occasionally, high levels of alkaline phosphatases also are found in patients with malignant tumors that ectopically express the enzyme (39). However, this is not the case in hepsin ${ }^{-1-}$ mice since they have not developed tumors. The increase of serum alkaline phosphatase in hepsin ${ }^{-/-}$mice could be due to impaired catabolism of alkaline phosphatase, since the liver is proposed to be responsible for the clearance of alkaline phosphatase from the blood (40). The mechanism of this process is not clear. If hepsin were responsible for the cleavage and removal of serum alkaline phosphatase, then hepsin deficiency could lead to the elevation of alkaline phosphatase in serum. Finally, the selective increase in bone alkaline phosphatase in hepsin ${ }^{-1-}$ mice (Fig. 4) suggests the possibility of certain skeletal disorders. In humans, for example, elevated alkaline phosphatase levels can be found in Paget's disease, osteomalacia, and rickets (39). In our study, x-ray examinations did not detect skeletal abnormalities in hepsin ${ }^{-1-}$ mice up to the age of $5 \mathrm{mo}$, but minor changes in bone density cannot be excluded completely. Further studies will determine whether skeletal abnormalities develop in older animals.

\section{Acknowledgments}

We thank L. Westfield (Howard Hughes Medical Institute, St. Louis, MO) for oligonucleotide synthesis, J. Xue (Washington University School of Medicine, St. Louis, MO) for stimulating discussions, J. McClary for DNA sequencing, M. Werner and P. Verhallen for assistance with mouse DIC models, V. Del Vecchio for assistance in histological studies, and B. Lillis and staff members of Animal Facilities at Berlex (Richmond, CA) for animal care. We also thank W. Dole and G. Rubanyi for their encouragement and helpful discussions.

J.E. Sadler is a Howard Hughes Medical Institute Investigator.

\section{References}

1. Bond, J.S. 1991. Plasma membrane proteases: introductory remarks. Biomed. Biochim. Acta. 50:775-780.

2. Chen, W.-T. 1993. Membrane proteases: role in tissue remodeling and tumour invastion. Curr. Opin. Cell Biol. 4:802-809.

3. Mignatti, P., and D.B. Rifkin. 1993. Biology and biochemistry of proteinases in tumor invasion. Physiol. Rev. 73:161-195.

4. Leytus, S.P., K.R. Loeb, F.S. Hagen, K. Kurachi, and E.W. Davie. 1988. A novel trypsin-like serine protease (hepsin) with a putative transmembrane domain expressed by human liver and hepatoma cells. Biochemistry. 27:10671074.

5. Kurachi, K., A. Torres-Rosado, and A. Tsuji. 1994. Hepsin. Methods Enzymol. 244:100-114.

6. Kraut, J. 1977. Serine proteases: structure and mechanism of catalysis. Annu. Rev. Biochem. 46:331-358.

7. Neurath, H. 1984. Evolution of proteolytic enzymes. Science. 224:350 357.

8. Appel, L.F., M. Prout, R. Abu-Shumays, A. Hammonds, J.C. Garbe, D. Fristrom, and J. Fristrom. 1993. The Drosophila Stubble-stubbloid gene encodes an apparent transmembrane serine protease required for epithelial morphogenesis. Proc. Natl. Acad. Sci. USA. 90:4937-4941.

9. Beaton, A., I. Kiss, D. Fristrom, and J.W. Fristrom. 1988. Interaction of the Stubble-stubbloid locus and the Broad-Complex of Drosophila melanogaster. Genetics. 120:453-464.

10. Tsuji, A., A. Torres-Rosado, T. Arai, S.-H. Chou, and K. Kurachi. 1991. Characterization of hepsin, a membrane bound protease. Biomed. Biochim. Acta. 50:791-793.

11. Tsuji, A., A. Torres-Rosado, T. Arai, M.M. Le Beau, R.S. Lemons, S.-H. Chou, and K. Kurachi. 1991. Hepsin, a cell membrane-associated protease: characterization, tissue distribution, and gene localization. J. Biol. Chem. 266: 16948-16953.

12. Zhukov, A., U. Hellman, and M. Ingelman-Sundberg. 1997. Purification and characterization of hepsin from rat liver microsomes. Biochim. Biophys. Acta. 1337:85-95.

13. Torres-Rosado, A., K.S. O'Shea, A. Tsuji, S.-H. Chou, and K. Kurachi. 1993. Hepsin, a putative cell-surface serine protease, is required for mammalian cell growth. Proc. Natl. Acad. Sci. USA. 90:7181-7185.

14. Tanimoto, H., Y. Yan, J. Clarke, S. Korourian, K. Shigemasa, T.H. Parmley, G.P. Parham, and T.J. O’Brien. 1997. Hepsin, a cell surface serine protease identified in hepatoma cells, is overexpressed in ovarian cancer. Cancer Res. 57:2884-2887. 
15. Kazama, Y., T. Hamamoto, D.C. Foster, and W. Kisiel. 1995. Hepsin, a putative membrane-associated serine protease, activates human factor VII and initiates a pathway of blood coagulation on the cell surface leading to thrombin formation. J. Biol. Chem. 270:66-72.

16. Wetsel, R.A., D.T. Fleischer, and D.L. Haviland. 1990. Deficiency of the murine fifth complement component (C5): a 2-base pair gene deletion in a $5^{\prime}$-exon. J. Biol. Chem. 265:2435-2440.

17. Mortensen, R.M., D.A. Conner, S. Chao, A.A.T. Geisterfer-Lowrance, and J.G. Seidman. 1992. Production of homozygous mutant ES cells with a single targeting construct. Mol. Cell. Biol. 12:2391-2395.

18. Capecchi, M.R. 1989. Altering the genome by homologous recombination. Science. 244:1288-1292.

19. Degen, S.J.F., L.A. Schaefer, C.S. Jamison, S.G. Grant, J.J. Fitzgibbon, J.-A. Pai, V.M. Chapman, and R.W. Elliott. 1990. Characterization of the cDNA coding for mouse prothrombin and localization of the gene on mouse chromosome 2. DNA Cell Biol. 9:487-498.

20. Hoffmann, W.E., N. Everds, M. Pignatello, and P.F. Solter. 1994. Automated and semiautomated analysis of rat alkaline phosphatase isoenzymes. Toxicol. Pathol. 22:633-638.

21. Davie, E.W. 1995. Biochemical and molecular aspects of the coagulation cascade. Thromb. Haemostasis. 74:1-6.

22. Chaing, S., B. Clarke, S. Sridhara, K. Chu, P. Friedman, W. VanDusen, H.R. Roberts, M. Blajchman, D.M. Monroe, and K.A. High. 1994. Severe factor VII deficiency caused by mutations abolishing the cleavage site for activation and altering binding to tissue factor. Blood. 83:3524-3535.

23. Wildgoose, P., K.L. Berkner, and W. Kisiel. 1990. Synthesis, purification, and characterization of an $\operatorname{Arg}_{152} \rightarrow$ Glu site-directed mutant of recombinant human blood clotting factor VII. Biochemistry. 29:3413-3420.

24. Broze, G.J., and P.W. Majerus. 1980. Purification and properties of human coagulation factor VII. J. Biol. Chem. 255:1242-1247.

25. Wildgoose, P., and W. Kisiel. 1989. Activation of human factor VII by factors IXa and Xa on human bladder carcinoma cells. Blood. 73:1888-1895.

26. Kisiel, W., K. Fujikawa, and E.W. Davie. 1977. Activation of bovine factor VII (proconvertin) by factor XIIa (activated Hageman factor). Biochemistry. 16:4189-4194.

27. Radcliffe, R., A. Bagdasarian, R. Colman, and Y. Nemerson. 1977. Activation of bovine factor VII by Hageman factor fragments. Blood. 50:611-617.

28. Broze, G.J., J.E. Leykam, B.D. Schwartz, and J.P. Miletich. 1985. Purifi- cation of human brain tissue factor. J. Biol. Chem. 260:10917-10920.

29. Wildgoose, P., Y. Nemerson, L.L. Hansen, F.E. Nielsen, S. Glazer, and U. Hedner. 1992. Measurement of basal levels of factor VIIa in hemophilia A and B patients. Blood. 80:25-28.

30. Eichinger, S., P.M. Mannucci, F. Tradati, A.A. Arbini, R.D. Rosenberg, and K.A. Bauer. 1995. Determinants of plasma factor VIIa levels in humans. Blood. 86:3021-3025.

31. Miller, G., J.C. Martin, K.A. Mitropoulos, M.P. Esnouf, J.A. Cooper, J.H. Morrissey, D.J. Howarth, and E.G.D. Tuddenham. 1996. Activation of factor VII during alimentary lipemia occurs in healthy adults and patients with congenital factor XII or factor XI deficiency, but not in patients with factor IX deficiency. Blood. 87:4187-4196.

32. Neuenschwander, P.F., and J.H. Morrissey. 1992. Deletion of the membrane anchoring region of tissue factor abolishes autoactivation of factor VII but not cofactor function. J. Biol. Chem. 267:14477-14482.

33. Morrissey, J.H., G. Macik, P.F. Neuenschwander, and P.C. Comp. 1993. Quantitation of activated factor VII levels in plasma using a tissue factor mutant selectively deficient in promoting factor VII activation. Blood. 81:734-744.

34. Fenton, J.W. 1986. Thrombin. Ann. NY Acad. Sci. 485:5-15.

35. Nakamura, T., T. Nishizawa, M. Hagiya, T. Seki, M. Shimonishi, A. Sugimura, K. Tashiro, and S. Shimizu. 1989. Molecular cloning and expression of human hepatocyte growth factor. Nature. 342:440-443.

36. Manfioletti, G., C. Brancolini, G. Avanzi, and C. Schneider. 1993. The protein encoded by a growth arrest-specific gene (gas6) is a new member of the vitamin $\mathrm{K}$-dependent proteins related to protein $\mathrm{S}$, a negative coregulator in the blood coagulation cascade. Mol. Cell. Biol. 13:4976-4985.

37. Schimidt, C., F. Bladt, S. Goedecke, V. Brinkmann, W. Zschiesche, M. Sharpe, E. Gherardi, and C. Birchmeier. 1995. Scatter factor/hepatocyte growth factor is essential for liver development. Nature. 373:699-702.

38. Uehara, Y., O. Minowa, C. Mori, K. Shiota, J. Kuno, T. Noda, and N. Kitamura. 1995. Placental defect and embryonic lethality in mice lacking hepatocyte growth factor/scatter factor. Nature. 373:702-705.

39. McComb, R.B., G.N. Bowers, Jr., and S. Posen. 1979. Alkaline Phosphatase. Plenum Press, New York. 986 pp.

40. Young, G.P., I.S. Rose, S. Cropper, S. Seetharam, and D.H. Alpers. 1984. Hepatic clearance of rat plasma intestinal alkaline phosphatase. Am. J. Physiol. 247:G419-G426. 